\title{
Neuroimaging Characteristics and Clinical Outcomes in Functionally Independent Patients Presenting with Oral Anticoagulant-Related Non-Traumatic Intracerebral Hemorrhage
}

Vasileios-Arsenios Lioutas, MD1 Nitin Goyal, MD² Aristeidis H. Katsanos, MD ${ }^{3,4}$ Christos Krogias, MD Ramin Zand, ${ }^{6}$ MD Vijay K Sharma, MD7 Panayiotis Varelas, MD ${ }^{8}$, Konark Malhotra, MD ${ }^{9}$ Maurizio Paciaroni, MD ${ }^{10}$ Aboubakar Sharaf, MD11 Jason Chang, MD ${ }^{12}$ Theodore Karapanayiotides, MD ${ }^{13}$ Odysseas Kargiotis, MD ${ }^{14}$ Alexandra Pappa, MD ${ }^{15}$, Abhi Pandhi, MD² Christoph Schroeder, MD', Argyrios Tsantes, MD ${ }^{16}$, Chandan Mehta, MD ${ }^{8}$ Magdy H. Selim, MD1 Andrei V. Alexandrov, MD ${ }^{2}$ Georgios Tsivgoulis, MD2,3

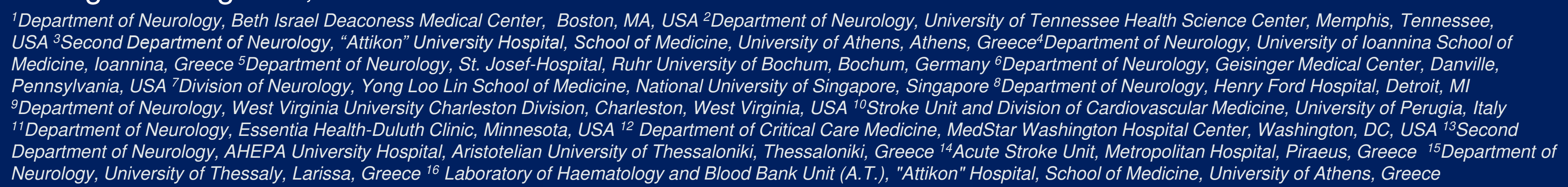

Introduction and Objectives

- Our group has previously reported smaller hematoma volume and lesser presenting neurologic deficit in patients with $\mathrm{ICH}$ due to new oral anticoagulants (NOACs) compared to vitamin $\mathrm{K}$ antagonists (VKA).

- We sought to prospectively validate our findings

\section{Methods}

- Prospective 12-month study in 15 tertiary stroke centers in the USA, Europe and Asia

- Systematic collection of demographic, clinical, laboratory neuroimaging data

- Functional outcome (90-day modified Rankin Scale)

- Outcomes of interest:

i. Hematoma volume, hematoma expansion ( $>12.5 \mathrm{ml}$ absolute or $>33 \%$ relative increase), perihematoma edema, midline shift

Presenting neurologic deficit (quantified by NIHSS; dichotomized as severe [NIHSS>10] vs non-severe) Hospital mortality

iii. 90 day functional outcome (modified Rankin Scale) and mortality

Included patients with premorbid functional independence (mRS $0-1)$

\section{Results}

- 196 patients: 62 NOAC-related (mean age $75.0 \pm 11.4$ years, $54.8 \%$ male) and 134 VKA-related (mean age $72.3 \pm 10.5$ years, $73.1 \%$ male).

- No differences in vascular comorbidities, HAS-BLED, CHA2DS2-VASc scores or antiplatelet and statin use; VKA-related ICH were more likely to be lobar $(60.4 \%$ vs $32.2 \%, p<0.001)$.

- significantly more frequent use of reversal agents (86.6 vs $48.4 \%$, $\mathrm{p}<0.001)$ in VKA-ICH

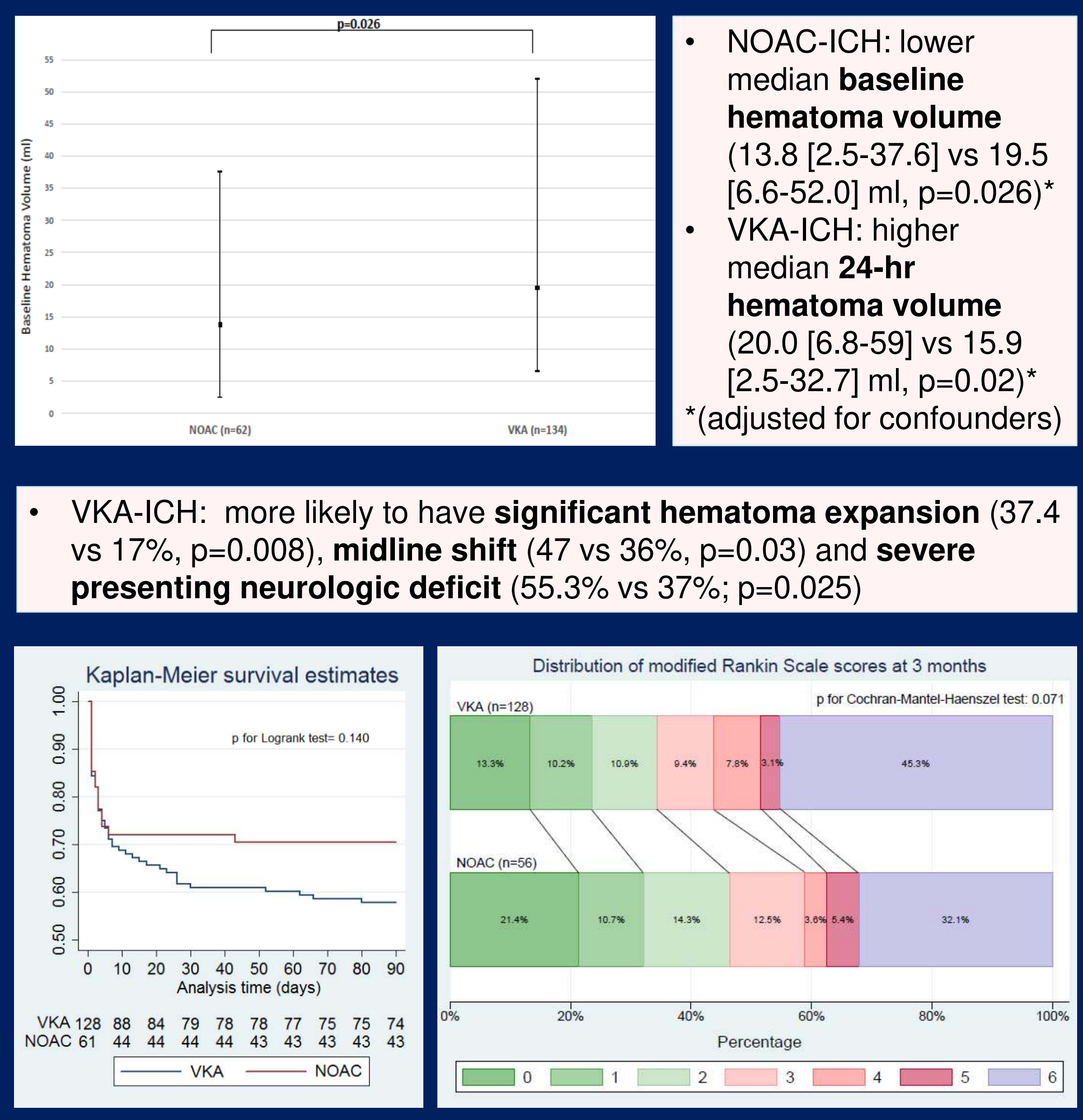

